\section{Medicinal plant Potentilla fulgens and its effect in vitro against Fasciola gigantica}

\author{
Pradeep Kumar*
}

Department of Zoology, S.G.N. Government P.G College, Muhammadabad Gohna, Mau-276403, UP, India

\section{Abstract}

Fascioliasis is a one of the most important serious parasitic zoonotic disease which caused by trematode giant liver fluke Fasciola hepatica and F. gigantica among cattle's and humans. The infection of Fasciola can be control by the use of phytochemicals as anthelmintic components. The anthelmintic activities of dried root powder of medicinal plant Potentilla fulgens and their different preparations (organic extracts and column purified fraction) are uses in vitro against liver fluke $F$. gigantica. The dried root powder, different organic extract, and column fractions were time and concentration-dependent. Among all the organic extracts, ethanol extract was high toxic than other organic extracts. The toxic effect of ethanolic extract of $P$. fulgens after $2 \mathrm{~h}$ exposure the $\mathrm{LC}_{50}$ value is $5.22 \mathrm{mg} / \mathrm{ml}$ against $F$. gigantica. The column purified fraction of dried root powder of $P$. fulgens shows more toxicity. The $2 \mathrm{~h} \mathrm{LC}_{50}$ of column purified fraction was 3.25 $\mathrm{mg} / \mathrm{ml}$ whereas in $8 \mathrm{~h}$ exposure the $\mathrm{LC}_{50}$ is $1.24 \mathrm{mg} / \mathrm{ml}$. The phytochemicals of the $P$. fulgens may be used as anthelmintic components against liver fluke $F$. gigantica.

\section{More Information}

*Address for Correspondence: Pradeep Kumar, Department of Zoology, S.G.N. Government P.G College, Muhammadabad Gohna, Mau-276403, UP, India, Email: pkumar_gpu@yahoo.co.in

Submitted: May 03, 2021

Approved: May 12, 2021

Published: May 13, 2021

How to cite this article: Kumar P. Medicinal plant Potentilla fulgens and its effect in vitro against Fasciola gigantica. Insights Clin Cell Immunol. 2021; 5: 004-007.

DOI: 10.29328/journal.icci.1001017

Copyright: (c) 2021 Kumar P. This is an open access article distributed under the Creative Commons Attribution License, which permits unrestricted use, distribution, and reproduction in any medium, provided the original work is properly cited.

Keywords: Potentilla fulgens; Fasciola gigantica; Fascioliasis; Anthelmintic activity

Check for updates

OPEN ACCESS

\section{Introduction}

The liver fluke Fasciola hepatica and F. gigantica is the causative agent of fasciolosis in cattle and human populations [1]. These diseases are parasitic in livestock with over 700 million production animals at risk of infection [2]. Fascioliasis is mainly related to plant-borne trematode digenetic zoonotic disease. The definite host of liver fluke is cattle, sheep, buffaloes, and goats which have an impact on the development, growth rate, the productivity of the ruminants and it's considered economically significant $[3,4]$. Fasciolosis is very common in the cattle population of the eastern part of Utter Pradesh, India [5-10]. In humans, the adult fluke of Fasciola causes a variety of symptoms such as long-standing fever, malaise, weight loss, eosinophilia, pain under the right costal margin, and anemia due to feeding on the blood [11].

Anthelmintic synthetic drugs can be used for the control of liver fluke infection, but it causes adverse effect on the host as well as develops resistant/residual effect in the fluke. Synthetic drugs are not easily available in some of the remote rural areas of developing countries [12]. The plant products or active phytochemicals are may be an effective anthelmintic component. Therefore, the use of the common medicinal plant as anthelmintic offers an alternative source that can solve these problems and it may be more acceptable due to eco-friendly and easily available for the users [13]. The medicinal plant Potentilla fulgens are commonly used as antihyperglycemic, antioxidant, antitumor, anti-hyperlipidemic, antiulcerogenic, anti-inflammatory, anthelmintic larvicidal, and molluscicidal [14-17]. The present study aims to evaluate the different preparations of medicinal plant $P$. fulgens in vitro treatments and their anthelmintic efficacy against the giant liver fluke F. gigantica.

\section{Material and methods}

\section{Collection of liver fluke (F. gigantica)}

The adult fluke $F$. gigantica $(3.2 \pm 0.18 \mathrm{~cm}$ in length) were collected from the infected bile ducts of the freshly slaughtered buffaloes from slaughterhouse district Gorakhpur (UP), India. The live fluke was kept in freshly prepared Hedon-Fleig (H-F) solution at $37 \pm 2{ }^{\circ} \mathrm{C}$ in a BOD incubator until use.

\section{Plants}

The dried root of the Potentilla fulgens was procured from the local market in Muhammadabad Gohna, district Mau (UP), India, and authenticity by Dr. A. K. Singh, Department of Botany, S.G.N. Government P.G. College, Muhammadabad Gohna, Mau, Uttar Pradesh. 


\section{Preparation of crude plant products}

The freshly dried root of $P$. fulgens washes through fresheater and dry under sunlight till to dry and cut into small pieces. The dried root pieces of $P$. fulgens were pulverized in the electric grinder machine and the crude powders thus obtained were used for the in vitro anthelmintic activity against $F$. gigantica.

\section{Organic solvent extracts}

Five gram dried powder of $P$. fulgens were extracted with $500 \mathrm{ml}$ each of $98.1 \%$ acetone, $97.8 \%$ ether, $98.6 \%$ chloroform, and $94.7 \%$ ethanol at room temperature for $48 \mathrm{~h}$. The solvents were removed under a vacuum machine and the following remaining dried parts were used for the determination of in vitro anthelmintic activity of $P$. fulgens and extract obtained 350 mg-ethanol, $360 \mathrm{mg}$-chloroform, $385 \mathrm{mg}$-ether, and 395 mg-acetone.

\section{Column purified-fractions}

One thousand milliliters of $94.7 \%$ ethanol were uses for the fractions of dried root powder of $P$. fulgens were subjected to silica gel through $5 \times 45 \mathrm{~cm}$ column chromatography (60-120 mesh, Qualigens Glass, Purchases from Precious Electrochemidus Private Limited, Bombay, India) for different fractions. One hundred milliliter fractions eluted with ethanol were collected. Ethanol from the column purified fractions was evaporated under a vacuum machine and the remaining solids column extracts were used for the determination of in vitro anthelmintic activity against Fasciola.

\section{Hedon-Fleig (H-F) solution}

The Hedon-Fleig (H-F) solution is used in this study which was prepared by the method of Hajare, et al. [18]. H-F solution contain NaCl-119.82 mM, $\mathrm{MgSO}_{4}-0.29 \mathrm{mM}, \mathrm{KCl}-4.01 \mathrm{mM}, \mathrm{CaCl}_{2}-$ $0.40 \mathrm{mM}, \mathrm{NaHCO}_{3}-17.8 \mathrm{mM}$, Glucose-22.3 mM, Streptomycin sulphate- 6900 unit $10 \mathrm{mg} / \mathrm{l}$ and Benzyl pencillin-9900 units/l at $38 \pm 2{ }^{\circ} \mathrm{C}$ in BOD incubator.

\section{In vitro toxicity determination}

In vitro toxicity of dried root powder, organic extract (acetone, ether, chloroform, methanol, and ethanol), and column purified-fraction of $P$. fulgens were performed in the petri dish by the method of Kumar and Singh, [19]. Six Petri dishes were setfor each concentration of different preparations of the $P$. fulgens against $F$. gigantica. Ten $F$. gigantica were kept in each Petri dish $(10 \mathrm{~cm} \times 1.5 \mathrm{~cm})$ containing $50 \mathrm{ml} \mathrm{H}-\mathrm{F}$ solution. Flukes were exposed to different concentrations of the different preparations (Table 1). The mortality of adult Fasciola was observed after $2 \mathrm{~h}, 4 \mathrm{~h}, 6 \mathrm{~h}$, and $8 \mathrm{~h}$ exposure. The control group of the experiment was kept in an equal volume of $\mathrm{H}-\mathrm{F}$ solution in a Petri dish under similar laboratory conditions but without treatment. The mortality of Fasciola was established by the opening of the sucker and contraction of the body. Usually in H-F solution in in vitro F. gigantica can survive up to $48 \mathrm{~h}$. Mortality of fluke was observed after $2 \mathrm{~h}$ up to $8 \mathrm{~h}$ were counted in treated and control groups.

In vitro, anthelmintic toxicity data were observed every $2 \mathrm{~h}$ up to $8 \mathrm{~h}$. The Lethal Concentration $\left(\mathrm{LC}_{50}\right)$ values, lower and upper confidence limits (LCL and UCL), slope values, and t-ratio value were calculated by the POLO computer program [20].

\section{Results}

In vitro anthelmintic activity of dried root powder of $P$. fulgens and their different preparations against F. gigantica was concentration and time-dependent. The lethal concentration $\left(\mathrm{LC}_{50}\right)$ values of dried root powder at $2 \mathrm{~h}, 4 \mathrm{~h}, 6 \mathrm{~h}$, and $8 \mathrm{~h}$ were $8.35,7.12,6.45$, and $5.78 \mathrm{mg} / \mathrm{ml}$, respectively (Table 1). Whereas, among all the organic extract (acetone, ether, chloroform, methanol, and ethanol) the ethanol extract were more toxic. The $2 \mathrm{~h}, 4 \mathrm{~h}, 6 \mathrm{~h}$, and $8 \mathrm{~h} \mathrm{LC}_{50}$ of ethanol extract of dried root powder of $P$. fulgens against $F$. gigantica were $5.22,5.02,4.88$, and $3.43 \mathrm{mg} / \mathrm{ml}$, respectively. The column purified fractions of dried root powder of $P$. fulgens were highly toxic. The $2 \mathrm{~h}, 4 \mathrm{~h}, 6 \mathrm{~h}$, and $8 \mathrm{~h}$ exposure the $\mathrm{LC}_{50}$ value of the column purified-fractions were observed 3.25, 2.65, 1.94 , and $1.24 \mathrm{mg} / \mathrm{ml}$, respectively (Table 1 ). The slope values given in table 1 were steep and the separate estimates of $\mathrm{LC}_{50}$ values based on each of the six replicates of the experiments were found to be within the $95 \%$ confidence limits of lethal concentrations. The t-ratio value is greater than 1.96 that indicates the significant anthelmintic efficacy of the various treatments (Table 1).

\section{Discussion}

The present study is demonstrated that the dried root powder, organic extracts, and column purified fractions of $P$. fulgens are potent sources of anthelminthic components against $F$. gigantica. It may be possible that active phytochemicals of the medicinal plant, $P$. fulgens are entering the body of fluke F. gigantica and cause mortality. In the treated group, all the preparations of the P. fulgens are cause significant toxicity in vitro against the $F$. gigantica (Table 1). But no mortality was observed in the control group. It indicates that the active phytochemicals of $P$. fulgens are entering through the tegument layer which caused paralysis and mortality of the fluke. The toxicity of different preparations of $P$. fulgens is time as well as concentration dependant as evident from the $\mathrm{LC}_{50}$ values and exposure period (Table 1 ). Higher toxicity of ethanol extract was observed among all organic extracts which indicate that the anthelmintic components P. fulgens are more soluble in ethanol organic solvent.

In vitro toxicity of the root powder of the $P$. fulgens and their different extract preparations are significant and cause antilarvicidal activities against sporocyst, redia, and cercaria larva of the F. gigantica [21]. In in vitro treatment at $2 \mathrm{~h}$ exposure, the highest toxicity was noted against sporocyst, 
Table 1: In vitro anthelmintic activity of dried root powder of $P$. fulgens and their different organic extract, column purified against $F$. gigantica at different exposure periods.

\begin{tabular}{|c|c|c|c|c|c|c|c|c|}
\hline \multirow[b]{2}{*}{$\begin{array}{l}\text { Exposure } \\
\text { periods }\end{array}$} & \multirow[b]{2}{*}{ Values } & \multicolumn{7}{|c|}{ In vitro exposure of Helminthicides (mg/ml) } \\
\hline & & $\begin{array}{l}\text { Potentilla fulgens } \\
\text { dried root powder }\end{array}$ & Acetone extract & Ether extract & Chloroform extract & Methanol extract & Ethanol extract & Column purified \\
\hline \multirow{5}{*}{$2 \mathrm{~h}$} & $\mathrm{LC}_{50}$ & 8.35 & 7.76 & 7.21 & 6.45 & 6.95 & 5.22 & 3.25 \\
\hline & LCL & 6.42 & 6.12 & 6.58 & 5.45 & 5.72 & 4.25 & 2.12 \\
\hline & UCL & 9.24 & 8.45 & 8.93 & 7.82 & 8.64 & 7.93 & 4.65 \\
\hline & Slope-value & $1.30 \pm 0.21$ & $1.12 \pm 0.20$ & $1.27 \pm 0.11$ & $1.18 \pm 0.19$ & $1.23 \pm 0.27$ & $1.19 \pm 0.17$ & $1.25 \pm 0.16$ \\
\hline & t-ratio & 3.45 & 4.32 & 3.55 & 4.11 & 3.23 & 3.96 & 4.12 \\
\hline \multirow{5}{*}{$4 \mathrm{~h}$} & $\mathrm{LC}_{50}$ & 7.12 & 6.45 & 6.37 & 5.86 & 6.01 & 5.02 & 2.65 \\
\hline & LCL & 6.89 & 5.35 & 5.37 & 4.61 & 4.65 & 4.12 & 1.75 \\
\hline & UCL & 8.23 & 7.91 & 8.32 & 6.94 & 7.74 & 7.53 & 3.24 \\
\hline & Slope-value & $1.14 \pm 0.18$ & $1.15 \pm 0.21$ & $1.26 \pm 0.29$ & $1.27 \pm 0.11$ & $1.19 \pm 0.24$ & $1.11 \pm 0.23$ & $1.31 \pm 0.25$ \\
\hline & t-ratio & 3.11 & 4.43 & 3.76 & 4.26 & 3.76 & 3.23 & 4.23 \\
\hline \multirow{5}{*}{$6 \mathrm{~h}$} & $\mathrm{LC}_{50}$ & 6.45 & 5.54 & 6.12 & 5.12 & 5.76 & 4.88 & 1.94 \\
\hline & LCL & 5.96 & 4.55 & 5.13 & 4.55 & 4.71 & 3.24 & 0.66 \\
\hline & UCL & 7.12 & 6.35 & 8.93 & 7.32 & 6.77 & 5.35 & 2.13 \\
\hline & Slope-value & $1.35 \pm 0.20$ & $1.33 \pm 0.19$ & $1.27 \pm 0.22$ & $1.18 \pm 0.35$ & $1.26 \pm 0.16$ & $1.39 \pm 0.26$ & $1.35 \pm 0.21$ \\
\hline & t-ratio & 4.54 & 3.14 & 4.54 & 3.23 & 3.65 & 4.87 & 4.53 \\
\hline \multirow{5}{*}{$8 \mathrm{~h}$} & $\mathrm{LC}_{50}$ & 5.78 & 4.87 & 5.86 & 4.95 & 4.64 & 3.43 & 1.24 \\
\hline & LCL & 4.86 & 3.24 & 4.32 & 3.91 & 3.74 & 2.46 & 0.56 \\
\hline & UCL & 6.31 & 6.51 & 7.43 & 5.88 & 6.27 & 4.99 & 2.02 \\
\hline & Slope-value & $1.26 \pm 0.19$ & $1.22 \pm 0.24$ & $1.26 \pm 0.17$ & $1.34 \pm 0.29$ & $1.17 \pm 0.24$ & $1.34 \pm 0.26$ & $1.32 \pm 0.26$ \\
\hline & t-ratio & 3.57 & 4.56 & 3.11 & 4.12 & 4.23 & 3.54 & 4.13 \\
\hline
\end{tabular}

Ten Fasciola gigantica in six batches were exposed in vitro ( $\mathrm{H}-\mathrm{F}$ solution) on different concentrations of the above anthelmintic preparations. Mortality of Fasciola was determined after every $2 \mathrm{~h}$ exposure period. LCL: Lower Confidence Limits; UCL: Upper Confidence Limits

redia, and cercaria the $\mathrm{LC}_{50}$ value of column extract were $62.42,59.25$, and $45.11 \mathrm{mg} / \mathrm{ml}$, respectively. It may be due to the uptake of the active moiety which progressively increases in the fluke body with an increase in the exposure period. It may be possible that the phytochemicals of the $P$. fulgens in the $F$. gigantica could change the different enzyme activity and cause effects. Many numbers of medicinal plants are have been used for the treatment of parasitic infection in animals and humans [22]. Kumar and Singh, [19] have been reported that in in vivo the common species Allium sativum, Ferula asafoetida, Syzygium aromaticum and their active components like allicin, ferulic acid, umbelliferone, and eugenol have anthelmintic activities against $F$. gigantica. The binary combinations (1:1 ratio) of the active components the allicin, ferulic acid, umbelliferone, and eugenol are more effective in vitro against the liver fluke $F$. gigantica [23]. The ethanolic root extract of $P$. fulgens is preventing gastric ulcers in rats due to $\mathrm{H}^{+} \mathrm{K}^{+}$-ATPase inhibitory and antihihistaminic activities [24]. The dried root powder of $P$. fulgens and their different organic extracts, column purified fractions are a potent source of the molluscicides which cause significant mortality against liver fluke vector snails Lymnaea acuminata and Indoplanorbis exustus [15-17]. Roy, et al. [25] have been reported that the alcoholic extract of dried root powder of $P$. fulgens has significantly reduced the vital tegumental enzymatic activity of the alkaline phosphatase, acid phosphatase, and adenosine triphosphatase (ATPase) in cestodes parasite Raillietina echinobothrida and trematodes Gastrothylax crumenifer. The root extract of $P$. fulgens has flavonoids and tannin in high amounts [26]. In vitro and in vivo studies have been evidence to support the anthelmintic effect which feeds the tannins and other polyphenols against abdominal and intestinal parasitic nematodes [27,28]. Athanasiadou, et al. [29] have been evaluated that tannin shows anthelmintic activities against infected sheep with Trichostrongylus colubriformis and causing larval mortalities. The compound of tannin in in vitro inactivates the enzyme activities in Trichostrongylus colubriformis larvae which are responsible for hatching and development [30]. Previously in different studies have been evaluated that the root extract of $P$. fulgens possesses antitumor [31], antioxidant [26], anthelmintic [25], and gastroprotective [24]. The root extract of $P$. fulgens in in vitro inhibit enzyme activities of amylase, $\alpha$-glucosidase, $\beta$-glucosidase, and lipase in the liver, kidney, and eye lens of the diabetic mice [32].

\section{Conclusion}

It can be concluded from the present study that the dried root powder of $P$. fulgens and their different organic extract and column purified fractions may be used as potent anthelminthic components for the control of liver fluke $F$. gigantica. This study also revealed a further study that the phytochemicals of the $P$. fulgens at the molecular level elucidate in the parasitic life of the liver fluke $F$. gigantica.

\section{References}

1. Phalee A, Wongsawad C, Rojanapaibul A, Chai J. Experimental life history and biological characteristics of Fasciola gigantica (Digenea: Fasciolidae). Korean J Parasitol. 2015; 53: 59-64. PubMed: https://pubmed.ncbi.nlm.nih.gov/25748710/

2. Chen JX, Chen MX, Ai L, Xu XN, Jiao JM. An Outbreak of Human Fascioliasis gigantica in Southwest China. PLoS ONE. 2013; 8: 71520. PubMed: https://pubmed.ncbi.nlm.nih.gov/23951181/

3. Kuchai JA, Chisnti MZ, Zaki MM, Rasool SAM, Ahmad J, et al. Some epidemiological aspects of fascioliasis among cattle of Ladakh. Global Vet. 2011; 7: 342-346. 
4. Eshetu EN, Thomas A, Awukew A, Goa, Buyako B. Study on the prevalence of Bovine Fascioliasis and Estimated financial loss due to liver condemnation: In case of Angacha Woreda, Kambata Tembaro Zone, Southern Ethiopia. J Biol Agric Healthcare. 2017; 7: 78-83.

5. Singh O, Agarwal RA. Toxicity of certain pesticides to two economic species of snails in northern India. J Economic Entomol. 1981; 74: 568571.

6. Kumar P, Singh DK. Molluscicidal activity of Ferula asafoetida, Syzygium aromaticum and Carum carvi and their active components against the snail Lymnaea acuminata. Chemosphere. 2006; 63: 1568-1574. PubMed: https://pubmed.ncbi.nlm.nih.gov/16310827/

7. Singh V, Singh DK. The effect of abiotic factors on the toxicity of cypermethrin against the snail Lymnaea acuminata in the control of fascioliasis. J Helminthol. 2009; 83: 39-45.

8. Kumar P, Singh VK, Singh DK. Enzyme activity in the nervous tissue of Lymnaea acuminata fed to different bait formulations. Am J Chem. 2012; 2: 89-93.

9. Singh RN, Kumar P, Kumar N, Singh DK. Efficacy of binary combination of deltamethrin+MGK-264 on levels of biochemical changes in the snai Lymnaea acuminata. Int J Pharm Pharmaceut Sci. 2020; 12: 111-116.

10. Vishwakarma AK, Kumar P. In vivo Anthelmintic Activity of Medicina plant Asparagus racemosus against Larva of Fasciola gigantica. Res J Agri Sci. 2021; 12: 675-680.

11. Ghoneim MA, El-kirdasy AF, Goher AK, Moussa WM, El-Ballal SS, et al Expression of cathepsin L1 Gene of Fasciola gigantica in different development stages. J Appl Sci Res. 2008; 4: 2017-2078.

12. Singh D, Swarnkar CP, Khan FA. Anthelmintic resistance in gastrointestinal nematodes of livestock in India. J Vet Parasitol. 2002; 16: $115-130$.

13. Hammond JA, Fielding D, Bishop SC. Prospects for plant Anthelmintics in tropical veterinary medicine. Vet Res Com. 1997; 21: 213-228. PubMed: https://pubmed.ncbi.nlm.nih.gov/9090048/

14. Kaul K, Jaitak V, Kaul VK. Review on pharmaceutical properties and conservation measures of Potentilla fulgens Wall. Ex Hook-a medicinal endangered herb of higher Himalaya. Indian J Nat Prod Resour. 2011; 2: 298-306.

15. Kumar P, Sunita K, Singh DK. Efficacy of Potentilla fulgens root powder and their different organic extract against fresh water vector snail Lymnaea acuminata. Asian J Animal Vet Adv. 2018a; 13: 3034.

16. Kumar $P$, Sunita K, Singh DK. Molluscicidal activity of different organic root extract of Potentilla fulgens against liver fluke vector snail Indoplanorbis exustus. Asian J Animal Sci. 2018b; 12: 30-35.

17. Kumar P. Effect of medicinal plant Potentilla fulgens against fecundity, hatchability and survival of Fasciola host snail Indoplanorbis exustus. Indian J Scienti Res. 2021; 11: 19-24.

18. Hajare SW, Lonare MK, Kumar D. Paralytic effect of Peganum harmala Linn. Alcoholic extract on Fasciola gigantica. J Vet Pharmacol Toxicol. 12; 11: 53-55.

19. Kumar $P$, Singh DK. In vitro anthelmintic activity of Allium sativum,
Ferula asafoetida, Syzygium aromaticum and their active components against Fasciola gigantica. J Biol Earth Sci. 2014; 4: B57-B65.

20. Robertson JL, Russell RM, Preciter HK, Savin NE. Bioassay with arthropods data, $2^{\text {nd }}$ Eds Taylar and Francis, CRC Press. 2007; 1-224.

21. Kumar P, Sunita K, Singh RN, Singh DK. Fasciola larvae: Anthelmintic activity of medicinal plant Potentilla fulgens against sporocyst, redia and cercaria. Asian J Adv Res. 2020; 3: 24-30.

22. Akhar MS, Zafar Iqbal Khan MN, Lateef M. Anthelmintic activity of medicinal plants with particular reference to their use in indo Pakistan sub continent. Small Rumin. 2000; 38: 99-107.

23. Kumar $P$, Sunita K, Singh DK. In vitro activity of different phytochemicals in binary combinations against Fasciola gigantica. Current Life Sci. 2016; 2: 58-63.

24. Hemalatha S, Laloo D, Prasad SK, Krishnamurthy S. Gastroprotective activity of ethanolic root extract of Potentilla fulgens Wall. Ex Hook. J Ethnopharmacol. 2013; 146: 505-514.

PubMed: https://pubmed.ncbi.nlm.nih.gov/23384786/

25. Roy B, Swargiary A, Syiem D, Tandon V. Potentilla fulgens (Family Rosaceae), a medicinal plant of North-East India: A natural anthelmintic. J Parasit Dis. 2010; 34: 83-88.

PubMed: https://pubmed.ncbi.nlm.nih.gov/21966126/

26. Jaitak V, Kaul VK, Himlata N, Kumar B, Singh J, Dhar, Sharma OP New hopane triterpenes and antioxidant constituents from Potentilla fulgens. Net Prod Commun. 2010; 5: 1561-1566. PubMed: https://pubmed.ncbi.nlm.nih.gov/21121248/

27. Hoste H, Jackson F, Athanasiadou S, Thamsborg SM, Hoskin SO. The effects of tannin-rich plants on parasitic nematodes in ruminants. Trends Parasitol. 2006; 22: 253-261. PubMed: https://pubmed.ncbi.nlm.nih.gov/16632404/

28. Hoste H, Martinez-Ortiz-De-Montellano C, Manolaraki F, Brunet S, Ojeda-Robertos N, et al. Direct and indirect effects of bioactive tanninrich tropical and temperate legumes against nematode infections. Vet Parasitol. 2012; 186: 18-27.

PubMed: https://pubmed.ncbi.nlm.nih.gov/22188981/

29. Athanasiadou S, Kyriazakis I, Jackson F, Coop RL. The effects of condensed tannins supplementation of foods with different protein content on parasitism, food intake and performance of sheep infected with Trichostrongylus colubriformis. Bri J Nutrit. 2001; 86: 697-706. PubMed: https://pubmed.ncbi.nlm.nih.gov/11749679/

30. Molan AL, Waghorn GC, Mcnabb WC. Effect of condensed tannins on egg hatching and larval development of Trichostrongylus colubriformis in vitro. Vet Rec. 2002; 150: 65-69.

PubMed: https://pubmed.ncbi.nlm.nih.gov/11837588/

31. Rosangkima G, Prasad SB. Antitumour activity of some plants from Meghalaya and Mizoram against Murine ascites Dalton's lymphoma. Indian J Exp Biol. 2004; 42: 981-988.

PubMed: https://pubmed.ncbi.nlm.nih.gov/15511001/

32. Majaw S, Challam SK, Syiem D. Effect of Potentilla fulgens L. on selective enzyme activities and altered tissue morphology in diabetic mice. J Morphol Sci. 2018; 38: 153-160. 